\title{
REFLEXÕES ACERCA DO DISCURSO SOBRE A EDUCAÇÃO*
}

Luciene Maria Bastos**

\section{RESUMO:}

$\mathrm{O}$ advento da modernidade configura rupturas históricas que inscrevem novas dimensões e tensões entre o homem e a sociedade. Desde então, grandes evoluções técnicas e científicas ocorreram, consubstanciando novos modos de ser, de pensar e de viver. No contexto atual, a evolução científica e tecnológica chegou a níveis nunca antes vistos. É a disseminação de um modo de produzir a vida que adquire movimento global, rompe as barreiras espaço-temporais e se difunde em ondas sísmicas com tal aceleração que já não há território em que não haja a marca de sua presença. Entretanto, este não é um movimento linear e similar em todos os contextos; impõe adaptações sociais, econômicas e culturais à sociedade. Inserida na cultura, a educação também sofre reorganizações, visando à adequação ao moderno nível tecnológico. A organização das Nações Unidas para a Educação, a Ciência e a Cultura (Unesco), órgão mundial que trata da educação, ciência e cultura, direciona as ações da primeira por meio do estabelecimento de diretrizes a serem adotadas. Nesse aspecto, o Relatório Delors (2001) constitui uma demarcação de objetivos para o século XXI. Esse texto visa ao questionamento da formação humana proposta no Relatório Delors, que é postulada como transmissão e socialização do conhecimento acumulado, sendo que este se desdobra em informações, habilidades e capacidades exigidas pelo movimento globalizante da modernidade. As reflexões que seguem estão fundamentadas, especialmente, no pensamento dos frankfurtianos Max Horkheimer e Theodor Adorno, buscando, no limite, indagar se o que está posto corresponde ao télos, ao sentido, da educação em sua essência.

Palavras-chave: Educação. Formação. Globalização. Reflexão.

\footnotetext{
* Artigo recebido em 22/03/2008 e aprovado em 30/09/2008.

** Mestre em Educação, professora da Universidade Estadual de Goiás, Unidade Universitária de Itaberaí. E-mail: lucienemeb@yahoo.com.br
} 
INTRODUÇÃO

O fim da Guerra Fria e a queda do muro de Berlim marcam a política internacional, que caminha de um mundo bipolarizado para um contexto em que se põe uma nova relação entre nação e mundo. Isso não retira os embates do contexto anterior; apenas os redimensiona. No mundo após a Segunda Guerra Mundial, configurava-se a necessidade de uma entidade para gerir as questões mundiais, finalidade com a qual foi criada, em 1945, a Organização das Nações Unidas (ONU), estrutura supranacional para administrar conflitos internacionais. Essa estrutura é integrada por organismos que atendem aos campos da política social, cultural e econômica. Dentro de seus vários organismos são criadas instituições, como o Banco Mundial (BM) e o Fundo Monetário Internacional (FMI), destinadas a apoiar financeiramente a recriação do sistema econômico mundial,

Inserida nessa estrutura, cria-se, em 1946, a Organização das Nações Unidas para a Educação, a Ciência e a Cultura (Unesco), cujos objetivos visavam à paz e à segurança entre as nações, mediadas pela educação, ciência e cultura e com o fim maior de alcançar a paz universal, "a justiça, o cumprimento da lei, assegurar os direitos humanos e as liberdades fundamentais em todos os povos do mundo sem distinção de raça, sexo, linguagem ou religião" (Thompson, apud Evangelista, 1997, p. 26).

Segundo Ianni (1995), a estrutura de poder que operacionaliza o sistema mundial é constituída de atores de todos os tipos: Estados nacionais, empresas transnacionais, organizações bilaterais e multilaterais, narcotráfico, terrorismo, grupo dos sete, Organização das Nações Unidas (ONU), Fundo Monetário Internacional (FMI), Banco Interamericano de Reconstrução e Desenvolvimento (BIRD), Organização Internacional do Trabalho(OIT), Organizações não-governamentais (ONG) e muitos outros. Todavia, os Estados nacionais ainda se constituem atores privilegiados, ainda polarizam muitas das relações e tensões que articulam o sistema mundial. "Daí a tese da interdependência das nações". A tese apóia-se no emblema da soberania do Estado-nação, cuja efetivação será definida no jogo das "relações, processos e estruturas" que compõem a sociedade global. Nessa medida, a tese de interdependência "funda-se na idéia de que o mundo, isto é, a coletividade das nações, em todas suas diversidades e desigualdades, pode ser visto como uma totalidade, um todo contemplando partes ou atores interdependentes" (IANNI, 1995, p.64). 
Nas discussões da Unesco no final da década de 1950 e na década de 1960, sob a influência das teorias da modernização e do capital humano, é articulada uma educação tecnificada, com vistas ao desenvolvimento econômico, e uma prática de planejamento educacional de longo prazo, consolidando a aproximação entre a Unesco e o Banco Mundial. ${ }^{1}$ Com o desenvolvimento do processo de modernização e tecnificação, a educação abandona progressivamente a referência ao conhecimento filosófico - o télos - para centrar-se em métodos e procedimentos das ciências naturais. Nas palavras de Evangelista (2003), "trata-se de racionalizar as estruturas dos sistemas de educação, a fim de articulá-los ao desenvolvimento integral, adequando-os ao atual estágio da civilização técnica e às possibilidades eminentes da prometida tecnologia espacial para a produção do consenso" (p.90).

Deve ser ressaltada a existência de elementos comuns nas resoluções e ações dos organismos envolvidos no processo de modernização e subsequente tecnificação, da educação, o qual não pode ser desvinculado da "ajuda internacional", que lhe confere certa unidade. ${ }^{2}$ A unidade é determinada, basicamente, por três elementos: primeiro, a preocupação em tornar a educação mais técnica e científica em razão do seu papel no desenvolvimento econômico; em segundo lugar, as desigualdades entre as nações, tornando a cooperação internacional um meio para atingir "a liberdade, a justiça social, a igualdade e a vida democrática" (EvANGELISTA, 1997, p.147); por último a idéia da existência de uma comunidade mundial à qual cabe possibilitar o desenvolvimento do progresso científico e tecnológico a todos os membros dessa comunidade.

Para consubstanciar a orientação para as ações da Unesco, são fundamentadas diretrizes destinadas a aprimorar a formação social existente. Nesse sentido, são realizados fóruns mundiais de discussão sobre a educação, que envolvem agências da ONU, como a Unesco, o Fundo das Nações Unidas para a Infância (Unicef), o Programa das Nações Unidas para o Desenvolvimento (PNUD), além do BM.

O primeiro fórum ocorre em Jomtien, na Tailândia, em 1990, com a Conferência Mundial sobre Educação para Todos. Nesse momento, são traçados planos e metas a serem alcançados pela educação no período de dez anos, a então denominada década da educação. Segundo o documento aprovado, a "Declaração Mundial sobre Educação para Todos", as necessidades básicas compreendem conhecimentos, habilidades, valores e atitudes necessários "para que os seres humanos possam sobreviver, 
desenvolver suas potencialidades, viver e trabalhar com dignidade, participar plenamente do desenvolvimento, melhorar a qualidade de vida, tomar decisões fundamentais e continuar aprendendo" (CONFERÊNCIA Mundial Sobre Educação Para Todos, 1993).

Os sistemas nacionais de ensino são reformados conforme as orientações dispostas nos fóruns mundiais assim como, periodicamente, os governos nacionais apresentam relatórios cujo objetivo é avaliar o desempenho em atingir as metas estabelecidas quanto à satisfação universal das necessidades básicas de aprendizagem. Ao tratar das reformas nos sistemas de ensino, Ianni (2004) relaciona a contundente inserção da educação, especialmente a educação formal, no contexto das relações e processos da intensificação da globalização no século XXI, bem como sua adaptação ao econômico.

Em diferentes gradações naturalmente, tendo-se em conta as peculiaridades sociais e as tradições de cada país, o Banco Mundial tem sido o agente principal para a definição do caráter "economicista", "privatista" e "tecnocrático" da reforma dos sistemas de ensino dos três níveis em curso na maioria dos países, desde os anos 50 do século XX e entrando pelo Século XXI. Reduzem-se ou mesmo abandonam-se os valores e os ideais humanísticos de cultura universal e pensamento crítico, ao mesmo tempo que se implementam diretrizes, práticas, valores e ideais pragmáticos, instrumentais, mercantis. Tudo o que diz respeito à educação passa a ser considerado como uma esfera altamente lucrativa de aplicação do capital; o que passa a influenciar decisivamente os fins e os meios envolvidos; de tal modo que a instituição de ensino, não só privada como também a pública, passa a ser organizada e administrada segundo a lógica da empresa, corporação ou conglomerado (IANNI, 2004, p.112).

As diretrizes para a educação estabelecidas nas discussões mundiais ressaltam, entre outros aspectos, a importância da educação básica para todos e insistem na modernização dos sistemas de ensino. A educação é aí apresentada como forma de atender às exigências fundamentais de uma sociedade em constante processo de modernização e, ao mesmo tempo, como conciliadora dos embates desse processo. 
Em 1996, em Nova Delhi, foi redigido o relatório intitulado "Educação um tesouro a descobrir"3 por uma comissão presidida por Jacques Delors, atendendo a uma solicitação da Unesco. O relatório tem a finalidade de

efetuar um trabalho de estudo e reflexão sobre os desafios a enfrentar pela educação nos próximos anos e apresentar sugestões e recomendações em forma de relatório [...] [que] deverá propor perspectivas, tanto políticas como relacionadas com a prática da educação, que sejam ao mesmo tempo inovadoras e realistas, tendo em vista a grande diversidade de situações, de necessidades, de meios e aspirações, segundo os países e regiões. Destinar-se-á, principalmente aos governos, mas sendo um dos objetivos tratar do papel da cooperação e da ajuda internacional em geral e, mais particular, do papel que cabe à Unesco, a comissão deverá também esforçar-se para formular, neste relatório, recomendações úteis aos organismos internacionais (Delors, 2001, p.272).

No Relatório Delors, encontram-se as diretrizes e as metas que devem nortear a educação neste século, que passam a estar presentes na legislação educacional da rede pública de ensino (balizando também a rede privada), norteando as reformas educacionais.

No ano de 2000, em Dakar, Senegal, foi realizada a avaliação da "Década da Educação", quando foram estendidos os prazos estabelecidos para que sejam atingidas as metas estabelecidas e cumpridos os compromissos firmados em Jomtien. Em última instância, os dois fóruns demonstram a preocupação (leia-se necessidade) de universalizar os instrumentos básicos para a educação, cujo objetivo maior é inserir os indivíduos e, posteriormente, a nação, no círculo econômico de desenvolvimento econômico mundial.

Conquanto a educação seja discutida nos fóruns mundiais como processo que transcende a instituição escolar e a preparação para o mercado de trabalho, sua vinculação ao setor econômico é mantida. Tal vinculação explicita-se à medida que as diretrizes estabelecidas nos fóruns insistem na modernização dos sistemas de ensino, enfatizada sob a forma de adaptação ao método e aos progressos da ciência moderna. Num momento de expansão do capital, é ressaltada a importância da universalização da educação básica como direito de todos. 
As transformações geo-históricas em curso no século XXI evidenciam o desenvolvimento da transnacionalização, da mundialização e da globalização. ${ }^{4}$ A intensificação do processo de globalização ocorrida nas últimas décadas, traz consigo contradições e embates, necessidades que precisam ser satisfeitas, assim como impõem adaptações sociais, econômicas e culturais à sociedade.

Nesse âmbito, a cultura passa a desenvolver-se em articulação com tal desenvolvimento científico e tecnológico. Segundo Horkheimer (1990), a cultura deve ser entendida como conceito dinâmico no qual o desenvolvimento humano e da sociedade coexistem numa relação de reciprocidade. A partir dessa reflexão, pode-se afirmar que a cultura abrange as marcas e problemáticas do curso histórico da vida humana e se expressa, de um lado, em sua forma particular de costumes, hábitos, mitos, crenças, instituições, língua, letras, artes, filosofia e ciências de um determinado povo ou região e, de outro lado, é manifestação do desenvolvimento da humanidade como espécie.

A educação, como amplo processo de socialização, via pela qual a cultura é transmitida, significada e recriada cotidianamente, movimento em que o homem cria a si mesmo como humano, também sofre reorganizações, visando à integração e à adaptação à racionalidade capitalista, à adequação a semelhante desenvolvimento tecnológico. A educação, sob essa conformação, perde sua essência de processo de formação humana, cuja finalidade é a contestação do real, sua reflexão e a criação de novas formas de existência. Para Adorno (2006), a educação vincula-se

evidentemente não à assim chamada modelagem de pessoas, porque não temos o direito de modelar pessoas a partir de seu exterior, mas também não a mera transmissão de conhecimentos, cuja característica de coisa morta já foi mais do que destacada, mas à produção de uma consciência verdadeira (AdORNo, 2006, p.141, grifos do autor).

Logo, a essência da educação, o télos, é a produção de uma consciência verdadeira, uma consciência crítica, que se diferencia da realidade exterior, nega-a e, assim, cria a si mesma e, ao mesmo tempo, a cultura. A consciência crítica diz respeito a ir além do que está posto, pensar sobre 
a realidade e a si mesmo, em contraposição ao pensamento afirmativo e sua conformação ao que existe. É isso que institui o sentimento de humanidade, ou seja, a efetivação da emancipação e liberdade na constituição do humano. ${ }^{5}$ Para Adorno (2006), "a única concretização efetiva da emancipação consiste em que aquelas poucas pessoas interessadas nessa direção orientem toda a sua energia para que a educação seja uma educação para a contradição e para a resistência" (p.183).

Pensando sob essa ótica, para Coêlho (2003), o sentido da educação assim como o da escola, se define pela realização de ambas como obras de cultura como espaços "da interrogação, da crítica, da criação" (p.7).

Pensada em seu ser, em seu sentido intrínseco, a educação é um processo em que os humanos são chamados a desenvolver, cultivar, realizar e confirmar sua humanidade, sem o que o desenvolvimento econômico e científico-tecnológico não terá grande valor e sentido. Educar é pensar o que há de humano e de bárbaro e degradante na humanidade, na existência pessoal e coletiva; é trabalhar para elevar o homem, suas instituições e criações à mais alta perfeição, à excelência (areté) dos gregos, traduzida por virtude (virtus) pelos romanos. Ao agir tendo em vista a realização desses fins que ele mesmo definiu para sua existência, o homem ultrapassa os limites de sua humanidade, ao mesmo tempo em que permanece e se afirma plenamente homem (ánthropos), transcende a realidade estreita e pobre de sua existência pessoal e social, inventando dimensões amplas, significativas, dignas e ricas (Cô̂LHo, 2003, p.7-8, grifos do autor).

É por meio da educação que o homem compreende e transforma o mundo, conferindo-lhe significado e inventando sua existência. Todavia, no contexto atual, a separação entre cultura, ciência e tecnologia fragmenta o conhecimento em áreas de ciências físicas e biológicas, de um lado, e as humanidades, de outro, o que retira o sentido de universalidade da formação humana e, consequentemente, empobrece a dimensão humanizadora da educação. A educação como cultura, civilização, processo de constituição do homem, impõe a conscientização do grave empobrecimento da formação humana e a busca de superação dessa realidade. Uma realidade que reduz a educação à transmissão de bens culturais que interessam ao mercado, baseada na sistematização e instru- 
mentalização de informações e habilidades. Sociedade do consumo e da mídia, a sociedade atual constitui o indivíduo mediante uma socialização baseada na heteronomia, efetivada sob uma excessiva preocupação com o imediato, o útil, o prático, tendo como objetivo o mercado, a produção e o consumo.

No desenvolvimento da sociedade, segundo Maar (2006), a ruptura da vinculação entre esclarecimento e liberdade, entre razão e emancipação, não se deve à ignorância, mas à "cumplicidade" entre o desenvolvimento da ciência e da cultura, de um lado, e a estrutura de dominação da formação social vigente, do outro, gerando uma aceitação que se dá objetivamente.

Semelhante desenvolvimento decorre do fato de efetuar-se, desde o início dos tempos modernos, um processo de formação do indivíduo, em grande medida pautado na afirmatividade do pensamento adaptado e adaptável ao statu quo, o que prejudica a elaboração de um pensamento crítico e questionador da realidade social em seu movimento histórico (HorkHeimer e Adorno, 1985).

Assim, para atender às necessidades do desenvolvimento econômico, a educação procura adequar-se às exigências de uma sociedade em constante processo de modernização e suas conseqüentes mudanças no mundo do trabalho. O sujeito, em grande medida, torna-se "prisioneiro" da produção de mercadorias, que passa a orientar a conduta e as referências de sua vida segundo os parâmetros e a lógica da sociedade capitalista, por meio da cultura - da educação, da religião, da política.

Nesse processo, no limite, o que está em causa é a construção e realização da hegemonia. Ocorre que a hegemonia tem estado cada vez mais sob o controle da estrutura internacional, de modo que "as organizações multilaterais e as corporações transnacionais são novas, poderosas e ativas estruturas mundiais de poder" (IANNI, 1998, p.19, grifos do autor). Notadamente, desloca-se o lugar da política. As decisões já não ocorrem em terreno nacional, hvendo o que o autor denomina desterritorialização e, num movimento subseqüente, a reterritorialização, ou seja, as adequações, em nível nacional, às decisões adotadas em âmbito mundial. A realidade social, nesse contexto, se descola, desenraiza, desterritorializa.

$\mathrm{Na}$ sociedade atual, solidifica-se uma cultura em que conflitos e contradições, aspectos constituintes da vida social e política, são considerados irracionais, verdadeiras anomalias. É possível observar tal 
concepção quando o Relatório Delors (2001), a atual orientação para as decisões relativas à educação, prioriza-a como "gestão inteligente e apaziguadora dos inevitáveis conflitos"(p.19). No Relatório são propostos os princípios que deverão fundamentar a educação no século XXI, os quais são expressos em quatro pilares: aprender a conhecer, aprender a fazer, aprender a ser e aprender a viver juntos, que devem pautar-se pelo conceito de educação ao longo da vida.

No contexto contemporâneo, momento de acirramento da globalização econômica, os avanços da ciência e da tecnologia produzem novas relações de dominação dos homens entre si e sobre a natureza. Consequentemente, ampliam-se, sob novas dimensões, as contradições e conflitos do movimento civilizatório do capitalismo.

$\mathrm{Na}$ essência da racionalidade do capitalismo, como modo de produção material e espiritual, como processo civilizatório, encontra-se sua irracionalidade, a sua negatividade, o seu absurdo. Pode-se falar em capital e trabalho, pobre e rico, centro e periferia, industrializado e subdesenvolvido, dominante e dependente, mas também se pode falar em produção e consumo, emprego e desemprego, afluência e pauperismo, integração e fragmentação, massificação e solidão (IANNI, 1999, p.65).

Nessa medida, a prerrogativa do Relatório Delors é enfatizar a necessidade de viver em paz, apresentada sob a forma do pilar aprender $a$ viver juntos. Num cenário em que prevalecem relações internas e externas de forças, é tecida a idéia de cooperação internacional, cuja efetivação depende do cumprimento da exigência de aprender a viver juntos nesta aldeia global (DELORS, 2001). Na busca de efetivação do pilar aprender a viver juntos, o Relatório Delors dispõe que é necessário ultrapassar as tensões entre local e nacional, universal e particular, tradição e modernidade, bem como a "tensão entre a indispensável competição e o cuidado com a igualdade de oportunidades" (op.cit. p.15). Dentro dessa perspectiva, é evidenciada a necessidade prioritária de gerir as contradições sociais em prol do desenvolvimento econômico, com vistas à preservação das relações internacionais de comércio.

Trata-se de aprender a viver juntos, desenvolvendo o conhecimento acerca dos outros, da sua história, tradições e espiritualidade. E a 
partir daí, criar um espírito novo que, graças precisamente a esta percepção das nossas crescentes interdependências, graças a uma análise dos riscos e dos desafios do futuro [...] Utopia, pensarão alguns, mas utopia necessária, utopia vital para sair do ciclo perigoso que se alimenta do cinismo e da resignação (Delors, 2001, p.19).

À educação é facultado o papel de conciliadora das contradições e embates conseqüentes da complexificação das relações sociais sob o capitalismo, visando uma convivência harmônica entre os povos. A rapidez em que flui a globalização, com a crescente e constante agilização das comunicações, tecnologias, intercâmbio de idéias e imagens modifica o andamento do devir, gerando a necessidade de investimentos numa educação que priorize a tarefa de formar para o respeito ao pluralismo, para a ética e para a valorização do humano. A questão latente é que as contradições sejam negadas como movimento inerente da história e da sociedade. Assim, para o Relatório Delors trata-se de "ultrapassar as principais tensões que, não sendo novas, constituem o cerne da problemática do século XXI" (2001, p.14).

Para ocultar as contradições e conflitos inerentes à constituição da sociedade é elaborado um discurso ideológico. ${ }^{6} \mathrm{~A}$ ideologia age no sentido de acomodar o indivíduo à realidade social e econômica sem maiores resistências. Segundo Horkheimer e Adorno (1973), a ideologia, como idéias que chegam ao indivíduo por meio da cultura, é uma consciência objetivamente necessária e, ao mesmo tempo, falsa; verdade e inverdade. Tal consciência pertence a uma sociedade de economia de mercado a qual se ergue e se alimenta de relações abstratas em que não pode transparecer sua verdade.

Com efeito, a Ideologia é justificação. Ela pressupõe, portanto, quer a experiência de uma condição social que se tornou problemática e como tal reconhecida mas que deve ser defendida, quer, por outra parte, a idéia de justiça sem a qual essa necessidade apologética não subsistiria e que, por sua vez, se baseia no modelo de permuta de equivalentes (HorkHEIMER e Adorno, 1973, p.191).

Nesse sentido, a ideologia integra o indivíduo às forças heterônomas da sociedade, cuja expressão maior é a administração da cultura. A questão latente no discurso ideológico não é o que está "por trás" das 
ações, mas o imaginário acerca delas que é tecido nas e pelas pessoas. A palavra é pensamento, expressa conceitos e princípios que são inculcados de maneira a criar idéias e valores que compõem o pensamento dos indivíduos em contextos determinados historicamente. Nesse sentido, a racionalidade ideológica oculta o verdadeiro sentido do discurso proferido pelas organizações mundiais, ofuscando o significado de que a burguesia capitalista apregoa valores cuja aceitação necessita para efetuar a harmonização ao existente e, assim, consolidar sua manutenção.

No movimento de harmonização e coesão com o real instituído, o Estado é elemento primordial. Segundo Chauí (1978), o Estado moderno figura como um poder que representa a si mesmo como uma instância separada do social, mas que, de fato, dá a esse social, identidade e homogeneidade. Portanto, a função do Estado é ocultar as contradições e conflitos que perpassam a divisão social e a luta de classes, representando-as como uma comum-unidade. De sorte que a divisão que é constitutiva da sociedade de classes é reduzida a um dado empírico e moral. O Estado sendo visto como um representante de toda a sociedade oculta o exercício do poder de uma classe sobre outras.

É construído um imaginário que representa a sociedade como idêntica, homogênea e harmoniosa. Assim, a ideologia fornece uma resposta ao desejo humano de identidade e ao temor de desagregação, em que o exercício de dominação é visto como natural, racional e legítimo. Para tal, a única forma é produzir uma imagem unificada da sociedade, com polarizações suportáveis e aceitáveis. Assim, o discurso ideológico tende a fixar determinados signos que neutralizam a contradição e afirmam a idéia de que o mundo é naturalmente harmonioso. Nesse prisma, a educação surge "como via que conduza a um desenvolvimento humano mais harmonioso, mais autêntico, de modo a fazer recuar a pobreza, a exclusão social, as incompreensões, as opressões, as guerras" (DELoRs, 2001, p.11). O imaginário construído escamoteia que as injustiças sociais são produtos do próprio desenvolvimento econômico; para além, advém da própria essência do modelo de produção, o qual apenas se mantém mediante a expropriação do trabalho humano.

Sob a racionalidade do discurso ideológico, o saber figura apenas como sistematização da realidade, em que pensar significa apenas apreender esse saber sistematizado mediante determinados procedimentos metodológicos. A partir dessa perspectiva, percebe-se que no discurso apresentado pelo Relatório Delors, mesmo quando a educação parece 
ser discutida de forma ampla, conforme se depreende do pilar aprender a ser ou da orientação da educação ao longo de toda a vida (DELORS, 2001), ela mantém o sentido de formação de capital humano, voltada à produtividade.

As comparações internacionais realçam a importância do capital humano e, portanto, do investimento educativo para a produtividade. A relação entre o ritmo do progresso técnico e a qualidade da intervenção humana torna-se, então, cada vez mais evidente, assim como a necessidade de formar agentes econômicos aptos a utilizar as novas tecnologias e que revelem um comportamento inovador. Requerem-se novas aptidões e os sistemas educativos devem dar resposta a esta necessidade (Delors, 2001, p.71).

A exigência feita à educação - que se reflete na escola - é a da preparação de um individuo flexível, pronto a assimilar as rápidas transformações da sociedade. Evidencia-se que a educação deve dar resposta a esta necessidade, isto é, deve suprir o mercado de trabalho de tais profissionais. É revelado o sentido da educação como preparação do individuo para acompanhar as transformações sociais, econômicas e não refletir e criticar tais transformações permanecendo a adaptação e controle do individuo.

De acordo com Adorno (2006), a adaptação deve ser entendida como fase inicial no processo de socialização de todo indivíduo, visto esse processo configurar a transmissão dos valores sociais que permitem a inserção do sujeito na sociedade. Entretanto, a questão premente é que na "sociedade administrada", a adaptação não ultrapassa essa fase de acomodação ao existente, gerando indivíduos ajustados e nada além. Indivíduos que não questionam o que existe, apenas aceitam o que está posto.

Nesta realidade, segundo Ianni (1998, p.25), formase o "cidadão do mundo, o cosmopolita, 'alheio' à política, mas produzido no jogo do mercado, como uma espécie de subproduto da lógica do capital”. Está em curso a formação de outro indivíduo, um diferente e problemático cidadão. Problemático, porque este indivíduo está inscrito em relações, processos e estruturas que se desenvolvem em escala mundial e envolvem a formação de uma totalidade histórica e lógica na qual o indivíduo perde a essência de ser eminentemente político. 
No contexto atual, segundo Ianni (1998), o individuo se alheia da “idéia e prática do espaço público, visto como instituição primordialmente política" (p.107). Para além, o indivíduo se alheia de si como ser político. $\mathrm{O}$ ser social limita-se ao indivíduo plenamente adaptado à realidade, cuja racionalidade prioriza a manutenção da coesão social, a imagem de identidade e harmonia, mas, dentro das imposições do desenvolvimento capitalista. A formação buscada nesse âmbito é a do mercado, a que capacite o indivíduo a inserir-se e adequar-se ao desenvolvimento cientifico e técnico econômico, efetuando, assim, um processo de formação limitado ao ajustamento ao real, que conduz à perda da individualidade, erigindo uma subjetividade permeada por um conformismo uniformizador.

A concepção de Ianni remete-nos ao sentido dos conceitos de cidadão e de cidadania dispostos no Relatório Delors (2001). Nesse, é evidenciado o sentido de que o cidadão é o indivíduo "preparado para acompanhar a inovação, tanto na vida privada como na vida profissional" (p.19). Nessa medida, o indivíduo deve pautar-se por aprender a viver junto, "respeitar a diversidade dos indivíduos e dos grupos humanos, mantendo, contudo, o princípio da homogeneidade" (p.51). Nesse sentido, é disposto que, como verdadeiro cidadão, cada pessoa deve participar da sociedade, da democracia sem esquecer, contudo, de desenvolver suas competências sociais, sem as quais a nação não atingirá o desenvolvimento econômico desejável. Aqui, não se ignora ou rechaça a importância desse desenvolvimento, mas não se pode perder de vista que o desenvolvimento econômico deve ser acompanhado do desenvolvimento social e humano.

Entretanto, na concepção disposta no Relatório Delors é excluído da educação, da formação humana o sentido de construção contínua de uma cidadania que nega, argüi e elabora o real e a política; política como práxis coletiva voltada ao bem comum e não ao interesse privado. Renega-se a política como característica não apenas dos governantes e que, antes, ela é uma característica constitutiva da vida humana, diz respeito a todo aquele que vive em comunidade, como definiu Aristóteles (1997). Inversamente, a educação prioriza a adaptação dos cidadãos à modernização-tecnificação, ignorando a reflexão sobre o sentido de semelhante desenvolvimento para a humanidade. Para Delors (2001), "os sistemas educativos devem dar resposta aos múltiplos desafios das sociedades da informação, na perspectiva de um enriquecimento contínuo 
dos saberes e do exercício de uma cidadania adaptada às exigências do nosso tempo" (p.68).

A ênfase na adaptação da educação à modernização e à formação que priorize o desenvolvimento científico e tecnológico, que capacite o indivíduo para as mudanças no trabalho, é uma necessidade que se põe desde as décadas de 1960 e 1970, momento de expansão científica e tecnológica que começa a exigir um novo trabalhador. $\mathrm{O}$ ensino tradicional não atendia a tais exigências, necessitando, então, se modernizar e se tornar mais dinâmico. Diante de tal exigência, o Relatório Faure (1972) elabora e explicita os conceitos de "educação permanente" e "cidade educativa" visando à adequação dos sistemas de ensino às necessidades de constante renovação. O objetivo era ampliar o tempo e o espaço de aprendizagem, pois era preciso "aproximar a vida da escola" (FAURE, 1972, p.32), visto que o sistema escolar fechado, recluso no espaço escolar, mostrava-se ineficiente para preparar o trabalhador flexível, com iniciativa e criatividade.

Essas são exigências que se modificaram e se modernizaram; as mudanças atuais no mundo do trabalho e na sociedade advindas da expansão científica e tecnológica, porém, continuam a exigir um novo trabalhador, um indivíduo totalmente adaptado às transformações de seu tempo. Ainda exige-se, apenas em novo patamar, a preparação de um trabalhador flexível, dinâmico, inovador e, principalmente, com grande capacidade de adaptação. Pode-se dizer, sob a ótica de Horkheimer e Adorno (1985) que, em essência, permanece a lógica da conformidade ao real instituído e legitimado pela racionalidade instrumental.

Em razão da contínua expansão econômica e a instauração de novas (leiam-se velhas) necessidades, o Relatório Delors (2001) retoma conceitos como educação permanente e cidade educativa ressaltados no Relatório Faure (1972). O conceito de cidade educativa é retomado sob a idéia de sociedade da informação. Por sua vez, o conceito de educação permanente é então apresentado como educação ao longo de toda a vida, com vistas a superar, primeiro, a separação entre formação geral escolar e a formação profissional técnica; segundo, a separação entre aprendizagem em espaço escolar e espaço extra-escolar (especialmente as empresas). Buscando essa superação, o Relatório Delors retoma a idéia que concebe o ensino e a aprendizagem como um continuum que se prolonga por toda a vida. 
Uma educação permanente, realmente dirigida às necessidades das sociedades modernas não pode continuar a definir-se em relação a um período particular da vida - educação de adultos, por oposição á dos jovens, por exemplo - ou a uma finalidade demasiado circunscrita - a formação profissional, distinta da formação geral. Doravante, temos de aprender ao longo de toda a vida e uns saberes penetram e enriquecem [...] É este continuum educativo, coextensivo à vida e ampliado às dimensões da sociedade, que a comissão entendeu designar, no presente relatório, pela expressão "educação ao longo de toda a vida" (Delors, 2001, p.103-4).

O conceito de educação ao longo de toda a vida diz respeito às necessidades criadas pelo progresso científico-tecnológico, que exige atualização contínua dos saberes, tornando obsoleta a formação existente. A qualificação em práticas e técnicas já não é suficiente. A aparente ampliação do conceito educação permanente para educação ao longo de toda a vida demonstra a preocupação em adequar a escola, que ainda se revela ineficiente, para satisfazer às exigências do mercado de trabalho em constante evolução. Assim, o referido conceito expressa que a preparação do trabalhador não deve restringir-se ao locus escolar bem como deve ser prolongado o tempo de atualização dos conhecimentos.

A educação ao longo de toda a vida refere-se a uma formação dinâmica, relacionada com a noção de competências. Nesse tipo de formação, são exigidas competências pessoais como, entre outros elementos, conhecimento intelectual, trabalho em equipe, capacidade de iniciativa, de criar soluções. Tais competências formariam uma espécie de coquetel individual no qual "as qualidades muito subjetivas, inatas ou adquiridas, muitas vezes denominadas 'saber-ser' [...] se juntam ao saber e ao saber-fazer para compor a competência exigida" (DELORS, 2001, p.94). A noção de competência é justificada no Relatório Delors como uma exigência advinda da "desmaterialização" do trabalho, ou seja, "a relação com a matéria e técnica deve ser completada com a aptidão para as relações interpessoais" (p.95).

O aparecimento e desenvolvimento de "sociedades da informação", assim como a busca do progresso tecnológico que constitui, de algum modo, uma tendência forte dos finais do século XX, sublinham a dimensão cada vez mais imaterial do trabalho e acentuam 
o papel desempenhado pelas aptidões intelectuais e cognitivas. [...] Trata-se, antes, de formar para a inovação pessoas capazes de evoluir, de se adaptar a um mundo em rápida mudança e capazes de dominar essas transformações (Delors, 2001, p.72).

A noção de competência, apresentada como a junção das exigências específicas do trabalho e da técnica com as aptidões do indivíduo às relações interpessoais e subjetivas, conduz à crítica de Horkheimer e Adorno (1985) sobre a conciliação do sujeito com o objeto. O sujeito deve adaptar suas aptidões interpessoais e subjetivas ao trabalho, o qual, por sua vez, torna-se cada vez mais subjetivizado, ou seja, ajustado às características do sujeito. É configurada, portanto, a fusão entre sujeito e objeto, entre trabalho e trabalhador, na qual ambos se anulam. Sob esse aspecto, a valorização das aptidões subjetivas (flexibilidade, criatividade, dentre outras), em razão das constantes mudanças na sociedade, demonstra que o conceito de educação ao longo da vida atende à necessidade peculiar do capitalismo, agora em novo momento, de adaptação do indivíduo ao existente e de conciliação com esse existente. Dessa maneira, prevalece o ajustamento e a dominação às tendências e exigências das transformações econômicas.

A ênfase na sociedade moderna como a sociedade da informação, que permeia todo o Relatório, remete-nos à análise de Adorno (2006) sobre a relação alienada e alienante entre tecnologia e sociedade. Segundo Adorno, "na relação atual com a técnica existe algo de exagerado, irracional e patogênico" (2006, p.132). A forma irracional com que o indivíduo se relaciona com a tecnologia atualmente é intensificada porque o fascínio com as descobertas tecnológicas e informáticas não tem limites.

Isto se vincula ao "véu tecnológico". Os homens inclinam-se a considerar a técnica como sendo algo em si mesma, um fim em si mesmo, uma força própria, esquecendo que ela é a extensão do braço dos homens. Os meios - e a técnica é um conceito de meios dirigidos à autoconservação da espécie humana - são fetichizados, porque os fins - uma vida humana digna - encontram-se encobertos e desconectados da consciência das pessoas (ADORNO, 2006, p.132). 
Justamente pela ofuscação de que a tecnologia é o braço prolongado do homem, sua utilização torna-se irracional. As grandes descobertas, os avanços da ciência, deveriam ser elementos que acrescentariam qualidades ao ser humano. Todavia, a autopreservação da espécie torna-se um fim em si mesmo, perdendo sua dimensão de humanização e convertendo-se em seu contrário: em elemento de desumanização do homem. O resultado de uma relação assim configurada é a dominação das relações humanas pela "fetichização da tecnologia". Os meios, a técnica, são fetichizados porque os fins, uma vida humana digna, encontram-se opacizados na consciência das pessoas, como afirmou Adorno.

Nesse sentido, a idéia da sociedade contemporânea como sociedade da informação povoa e organiza o imaginário dos indivíduos e coletividades criando a crença de que o mundo seja uma espécie de aldeia global". Aldeia cujo signo por excelência parece ser a comunicação, o que pode ser expresso pela generalização dos meios impressos e eletrônicos articulados em teias multimídias que alcançam o mundo todo. Assim, a suposta universalização das condições e possibilidades reforça a noção exposta pelo Relatório Delors (2001) de que a adaptação ao contexto da globalização proporciona igualdade de condições para o conhecimento, para a educação e, consequentemente, para o sucesso no mercado de trabalho. A questão premente é: que conceito de conhecimento, de educação e de formação balizam a orientação para a educação mundial expressa no Relatório?

Conquanto a concepção de conhecimento apresentada no Relatório Delors (2001), a qual se pauta pelos quatro pilares do conhecimento, enalteça o sentido crítico e vincule a autonomia à capacidade de discernir, o próprio sentido crítico e a autonomia estão interligados à instrumentalização científica, a qual, por sua vez, encontra-se aliada às prerrogativas do progresso capitalista. Apesar de ser admitido no Relatório que o simples desenvolvimento econômico não garante o desenvolvimento humano e que a sociedade pautada na tecnologia é uma sociedade do efêmero, persiste o sentido e a priorização da passagem para uma sociedade cognitiva. Sociedade que deve primar pela busca de "uma iniciação precoce à ciência, aos seus métodos de aplicação, ao difícil esforço para dominar o progresso" (Delors, 2001, p.17). Aí, o conhecimento se restringe à codificação de informações.

Nesse aspecto, Hannah Arendt (2000) diferencia conhecimento ou cognição de pensamento, a partir da distinção kantiana entre razão 
(Vernunft) e intelecto (Verstand). Segundo a autora, o intelecto deseja apreender o que é dado aos sentidos, mas a razão, o pensamento quer compreender seu significado.

Quando distingo verdade e significado, conhecimento e pensamento, e quando insisto na importância dessa distinção, não quero negar a conexão entre a busca de significado do pensamento e a busca de verdade do conhecimento. Ao formular as irrespondíveis questões de significado, os homens afirmam-se como seres que interrogam. Por trás de todas as questões cognitivas para as quais os homens encontram respostas escondem-se as questões irrespondíveis que parecem inteiramente vãs e que, desse modo, sempre foram denunciadas (ARENDT, 2000, p.48).

Assim, a atividade do conhecimento, afirma ainda Arendt, deixa atrás de si um tesouro acumulado e retido pela civilização, mas a atividade do pensamento não deixa rastro e, portanto, a necessidade de pensar jamais pode ser exaurida.

A distinção feita por Arendt, em relação à "sociedade da informação" ou sociedade cognitiva enfatizada pelo Relatório Delors, evidencia um dimensionamento da humanidade restrito à esfera do conhecimento e da cognição, isto é, da busca de verdades irrefutáveis. É negligenciado o significado, o sentido, o questionamento da realidade dada aos sentidos e, principalmente, o pensar para além dessa aparência. A busca não é transcender o imediato, ao contrário, a ordem é prender-se a esse imediato. A fixação na realidade imediata, no fragmento, não permite a compreensão do todo social e suas contradições.

O Relatório Delors (2001) ressalta os problemas de uma sociedade que se desenvolve no que concerne às conquistas científicas e tecnológicas, enquanto enfrenta o crescimento da violência, da fome, das guerras e da miséria e atribui à educação e à escola a função de adaptar o individuo às transformações dessa sociedade. Diante de tal prerrogativa, $o$ Relatório afirma:

este relatório surge numa altura em que a humanidade, perante tantas desgraças causadas pela guerra, pela criminalidade e pelo subdesenvolvimento, hesita entre a fuga para a frente e a resignação. Vamos propor-lhe uma outra saída. Tudo nos leva, pois, a dar 
novo valor à dimensão ética e cultural da educação e, desse modo, a dar efetivamente a cada um, os meios de compreender o outro, na sua especificidade, de compreender o mundo na sua marcha caótica para uma certa unidade. Mas antes, é preciso começar por se conhecer a si próprio, numa espécie de viagem interior guiada pelo conhecimento, pela meditação e pelo exercício da autocrítica. Esta mensagem deve orientar qualquer reflexão sobre educação, em conexão com o desenvolvimento e ao aprofundamento da cooperação internacional, no âmbito da qual se alcançarão as soluções aqui propostas (DeLors, 2001, p.16-7).

Apesar da ênfase ao exercício da autocrítica, à valorização da dimensão estética e cultural da educação, fica evidente a necessidade de imbuir a educação de um sentido harmonizador, conciliador das contradições que são inerentes à globalização, ao próprio progresso capitalista. O discurso não denota a concepção da educação como formação que busca o télos, o sentido crítico como questionamento da realidade, de sua gênese e de sua lógica. Contrariamente, a formação proposta é voltada à preparação dos indivíduos à adaptação ao existente. A educação, na concepção proposta, é reduzida à escola, especialmente à educação básica, em que são traçados metas e projetos de curto prazo e que atinjam todos os indivíduos da sociedade, em razão do desenvolvimento econômico ter urgência de resultados. Mesmo ao afirmar a finalidade de uma formação humana voltada ao cultivo da crítica e da autonomia, essa possibilidade fica reduzida em razão do ocultamento das contradições sociais, desviando a educação do sentido proposto por Adorno (2006, p.183) de direcionar a educação "para a contradição e para a resistência", quando afirma sua vinculação à conscientização e à emancipação.

Na qualidade de discurso atual da educação, os quatro pilares apresentados no Relatório Delors (2001) - aprender a conhecer, aprender a fazer, aprender a ser e aprender a viver juntos - numa visão conjunta, parecem ter como finalidade última a realização da essência humana. Entretanto, o pilar aprender a conhecer está ligado ao conhecimento utilitário difundido na sociedade. A afirmação "aprender a conhecer e aprender a fazer são, em larga medida, indissociáveis" (p.93); quando o aprender a fazer refere-se a competências e qualificações, evidencia que o conhecimento proposto vincula-se à formação para utilização de novas técnicas e tecnologias. A ênfase é no conhecimento científico-pragmático. 
A vinculação do conhecimento ao pragmatismo revela sua dimensão de afirmação do existente, pois esta teoria, ao postular a utilidade e a experiência empírica como parâmetro do conhecimento, liga-se de forma imediata ao dado imediato e a sua descrição. Em conseqüência da identificação entre o conhecimento e o existente, ocorre a perda da experiência. Todavia, não a experiência como experimentação empírica, mas a própria experiência do pensamento. Para Adorno (2006), o que caracteriza propriamente a consciência é o ato de pensar a realidade, isto é, fazer experiências.

Este sentido mais profundo de consciência ou faculdade de pensar não é apenas o desenvolvimento lógico formal, mas ele corresponde literalmente à capacidade de fazer experiências. Eu diria que pensar é o mesmo que fazer experiências intelectuais. Nesta medida e nos termos que procuramos expor, a educação para a experiência é idêntica à educação para a emancipação (ADORNO, 2006, p.151).

Pode-se inferir que, para Adorno, experiência significa auto-reflexão, crítica imanente e contínua da realidade social, negação do conteúdo social como dado imutável. Tal experiência constitui, dessa forma, a construção de um eu forte, ou seja, uma subjetividade que, em contato com as conformações sociais, tem capacidade de escolher, refletir, argüir e agir com crítica, ou seja, uma subjetividade que nega o que está posto, diferenciando-se da realidade em que se insere.

Paradoxalmente, no Relatório Delors (2001), as experiências do indivíduo, seu "ser", restringem-se às capacidades cognitivas necessárias ao momento atual do desenvolvimento capitalista como memória, raciocínio, facilidade de comunicação, dentre outras. A questão essencial é que se trata de fornecer "referências intelectuais que [...] permitam compreender o mundo" (Delors, 2001, p.100). A finalidade da educação, portanto, fica limitada à compreensão do mundo, legitimando esta representação como verdade. A racionalidade posta na realidade passa a ser a verdade absoluta e transparente. Nesse sentido, a experiência que forma o ser humano e produz "conhecimento" restringe-se a conhecer o dado, o concreto empírico.

Maar (2006), ao analisar o pensamento adorniano referente à formação cultural, afirma que a experiência formativa "pressupõe uma 
lógica da não-identidade, uma inadequação - no curso da experiência pela qual a realidade efetiva se forma - entre realidade e conceito, entre a existência e sua forma social" (p.25). Assim, a experiência formativa é caracterizada pela complexa relação entre o condicionamento social, isto é o momento de adaptação, e o sentido autônomo da subjetividade, o momento da negação e resistência. Ocorre que tal relação é rompida e a resistência se perde, permanecendo apenas o momento de adequação à dominação social. Nesse contexto de ausência de experiência formativa, produzem-se condições sociais que tendem a impossibilitar a formação cultural (Bildung), a formação humana do sujeito. Um contexto em que, na debilidade do pensamento se encontra o potencial de enquadramento e subordinação ao statu quo.

É preciso ressaltar que a perda da capacidade de fazer experiências formativas não é algo imposto de fora à sociedade, acidental, nem é provocado por intenções subjetivas, mas corresponde a uma tendência objetiva da sociedade, ou seja, ao próprio modo de produzir-se e reproduzir-se daquela. Nesse process, a cultura é profundamente afetada, o que implica em radical redução de sentido da educação. No âmbito dessa redução, situa-se a crítica de Adorno.

Adorno põe em relevo que a educação perdeu o seu sentido, já não sendo este compreensível por si mesmo, tendo agora que se ligar a uma finalidade exterior. A partir do momento em que a educação se liga a modelos e tendências exteriores a sua essência, ela passa a compactuar com a heteronomia, com "o momento autoritário, o que é imposto a partir do exterior" (ADORNO, 2006, p.141). Nesse sentido, a educação encontrase em contradição com a formação do homem autônomo, emancipado, no sentido kantiano.

Ao fim e ao cabo, percebe-se que o discurso proferido pelo Relatório Delors, o qual faz parte de uma orientação mundial, é contraditório em seu todo. Ao mesmo tempo em que afirma valorar a "dimensão ética e cultural da educação" e propor uma formação "guiada pelo conhecimento, pela meditação e pelo exercício da autocrítica” (2001, p.16), demonstra que sua prioridade é a "iniciação precoce à ciência, aos seus métodos de aplicação". Como pode ser essa uma formação voltada ao desenvolvimento humano para a ética e a autonomia, se a educação e o conhecimento são banalizados e instrumentalizados?

A percepção das contradições no discurso proferido, que vem se delineando há décadas, levam ao encontro da crítica adorniana segundo 
a qual, de fato, a formação em voga é, em grande medida, uma pseudoformação. Uma formação que cria um sujeito identificado a uma socialização que privilegia a padronização e a homogeneização em relação à realidade social. Aí, a formação é anulada pelo esfacelamento da experiência formativa, resultando no extermínio do diferenciado em prol da intensa integração do indivíduo ao existente. Para Adorno (1966), a formação cultural converteu-se

em uma pseudoformação socializada, na posição do espírito alienado, que, segundo sua gênese e seu sentido, não precede a formação cultural, mas a sucede. Desse modo, tudo fica aprisionado nas malhas da socialização e nada na natureza permanece sem forma; mas sua rusticidade - a velha ficção - mantém a vida e se reproduz de maneira ampliada: símbolo de uma consciência que renunciou à autodeterminação, se prende obstinadamente a elementos culturais aprovados, que gravitam sob seu malefício, como algo decomposto em direção à barbárie. [...] Inclusive a pseudoformação passou a ser a forma dominante da consciência atual, apesar de toda ilustração e de toda informação que se difunde - e também com sua ajuda, o que exige uma teoria que veja o todo mais amplamente (ADORNo, 1966, p.175-176). ${ }^{7}$

A constituição do indivíduo sob a pseudoformação é deturpada e ele não se diferencia do universo social; apenas o repete e o aceita, numa constituição presa às necessidades econômicas do capital, cuja prioridade, para que esse modo de produção continue sua marcha evolutiva, é a conciliação das contradições sociais. Nesse sentido, a exigência feita à educação, à cultura, expressa nas diretrizes expostas no Relatório Delors, é uma formação baseada na homogeneização, na criação de um indivíduo flexível, pronto a assimilar as rápidas transformações da sociedade, suprindo o mercado de profissionais que impulsionem o desenvolvimento econômico. É camuflado que o indivíduo deve acompanhar as mudanças e reestruturações sociais e econômicas, mas não refletir ou posicionar-se diante de tais transformações. É obnubilada que a autonomia é substancialmente restringida em prol da adaptação e aceitação.

Para Maar (2006), Adorno preocupa-se em advertir que a formação da subjetividade autônoma pela via da educação e da cultura nos parâmetros da sociedade burguesa, sem o apoio de uma crítica objetiva da 
própria formação social, tende a ser inviável. A educação deve ser uma educação política, rompendo com a educação como mera apropriação de um instrumental técnico voltado à eficiência, para ser um aprendizado "aberto à elaboração da história e ao contato com o outro não-idêntico, o diferenciado" (MAAR, 2006, p.27).

Para Adorno (2006), a educação para a resistência, para a emancipação, em razão do contexto ideológico atual, que já se tornou o próprio real, necessita primordialmente de conscientização, pois, "se não quisermos aplicar a palavra 'emancipação' num sentido meramente retórico [...], é preciso começar a ver efetivamente as enormes dificuldades que se opõem à emancipação nesta organização do mundo" (p.181). Logo, é o reconhecimento das contradições que persistem na própria educação, assim como o reconhecimento da dominação em que a sociedade se encontra, que abre a possibilidade de emancipação, de autonomia. A busca é de superação do existente.

A partir de tal conscientização, deve-se buscar o sentido, o télos da educação, cuja essência é interrogar, negar e afirmar o saber, a realidade, a vida. É fundamental, nessa busca, não confundir a educação com uma de suas formas, a escola. Como afirma Coêlho (2003), para efetivar a educação como dimensão que engloba todos os processos e relações sociais em que o homem, como ser genérico, compreende, significa, cria e recria seu viver e o mundo ao seu redor. Nesse processo o homem - o ánthropos - se faz humano.

Esta é uma reflexão que se faz urgente, pois as pessoas tendem a considerar que o simples desenvolvimento econômico e científicotecnológico redunda em vida melhor para a humanidade, quando o próprio sentido de humanidade se perdeu. Os valores éticos, morais, verdadeiramente humanos, têm sido excluídos do cotidiano das pessoas, priorizando-se as relações comerciais que se estendem por todas as esferas da vida.

\section{ABSTRACT}

The onset of modernity has brought in its wake historical ruptures that have introduced new dimensions and tensions between people and society. Since then, important techno-scientific evolutions have occurred, consolidating new ways of being, thinking and living. In the present context, scientific and technological evolution has reached unprecedented levels. It is the spreading 
of a new way of producing life on a global scale breaking barriers of time and space and spreading in seismic waves so fast that no single place is left without marks of its presence. However, it is not a linear movement similar in all kinds of context. It imposes social, economic and cultural adaptations on society. Rooted in culture, education also undergoes changes in order to adapt to this new modern technological level. Unesco, the global agency which deals with education, science and culture, directs the lines of action of education throughout the world through its policies. Among these is the Delors Report (2001) which states the objectives for the $21^{\text {st }}$ century. This study sets out to question the kind of human education proposed by the Delors Report, which sees education as the mere transmission and socialization of accumulated knowledge which becomes the information, abilities and skills demanded by the globalizing movement of modernity. The reflections that follow are based, especially, on the thinking of the Frankfurtians Max Horkheimer and Theodor Adorno, and seek, at the outset, to investigate if what is put forward corresponds to the télos, the essence and meaning of education.

Keywords: Education. Formation. Globalization. Reflection

\section{NOTAS}

1. Segundo a perspectiva do Banco Mundial, a função social da educação reduzse à adequação de meios, técnicas, métodos e metodologias direcionadas para atingir o desenvolvimento econômico dos países assistidos por ele. A educação é vista como elemento determinante do desenvolvimento econômico, de forma que a educação básica torna-se o principal caminho para tornar os países aptos à participação no desenvolvimento capitalista, convergindo no foco de investimentos (IANNI, 2004).

2. O processo de tecnificação da educação constitui-se a partir das ações de diversos organismos, que se propõem "ajudar ou cooperar" no desenvolvimento econômico, social e educacional das nações. Entre esses organismos destaca-se o Instituto de Solidariedade Internacional (ISI), da Fundação Konrad Adenauer (FKA), da República Federal da Alemanha, cuja contribuição para a modernização educacional na América Latina materializou-se no Projeto Brasileiro e Latino-Americano de Teleducação. A "ajuda" norte-americana não pode ser desvinculada do processo de construção da hegemonia dos EUA sobre o mundo capitalista a partir da Segunda Guerra Mundial, dentro do contexto de bipolarização do mundo em torno do eixo leste-oeste (URSSEUA). Dentro de tal perspectiva situa-se a ajuda dos EUA à Europa por meio do plano Marshall, cuja implantação ganha viabilidade com a criação, em 1948, da organização Européia para a Cooperação Econômica (OECE), que 
passa a promover os acordos bilaterais da "ajuda americana". Entretanto, os acordos evidenciam que a "ajuda" favorece os interesses de dominação dos EUA, uma vez que estabelecem "as obrigações particulares de cada país, abrindo possibilidade de vantagens unilaterias em favor dos EUA na relação bilateral com os países participantes da organização" (EvANGELISTA, 1997, p.37). Evangelista diz ainda que a ajuda internacional prossegue e "rearticula-se na década de 1960 com a Aliança para o Progresso e é complementada em toda a América Latina com a ação da Usaid, que se notabiliza, no Brasil, pelos conhecidos acordos MEC-Usaid" (1997, p.49).

3. Convém destacar que este Relatório será mencionado conforme o nome de seu organizador, o presidente da comissão (DELoRs, 2001).

4. Mundialização e globalização são dois processos distintos, mas íntima e contraditoriamente relacionados. Globalização se refere ao modo de produção assim como constitui também processo civilizatório e, como tal, só se torna possível à medida que se mundializa, isto é, se difundir aspectos culturais (modos de ser, pensar, e agir modernos) necessários à manutenção e à reprodução desse modo de produção. Em razão de o modo de produção capitalista necessitar difundir-se na esfera do consumo, é engendrada a cultura do consumo, quel diz respeito à formação de mentes adaptadas e adaptáveis. Segundo Ianni (1995), "mundialização é também e sempre modernização, mas modernização nos moldes do capitalismo ocidental" (p.17).

5. A emancipação, a autonomia, para Adorno (2006), tem seu fundamento em Kant, que a define como "a saída do homem da sua menoridade, de que ele próprio é culpado. A menoridade é a incapacidade de servir-se do entendimento sem a orientação de outrem" (KANT, 2004, p.11). Assim, a autonomia refere-se ao cultivo da própria reflexão.

6. Segundo Chauí (1978), é no interior da sociedade burguesa, nascida em meados do século XIV, que pode ser circunscrita a origem da ideologia. Neste momento histórico, a origem da sociedade perde sua explicação mítica e teológica. É elaborado, então um discurso do social e do político que se torna um corpo de representações nas quais o sujeito se reconhece, pois essas explicam a origem e as relações sociais, políticas e econômicas. No entanto, essas explicações ocorrem de modo imediato, assim, o aparecer (o fenômeno) social é considerado como o próprio ser (conceito) do social. "Esse aparecer não é 'aparência' no sentido de que seria falso, mas é uma aparência no sentido de que á maneira pela qual o processo oculto que produz e conserva o social se manifesta para os homens" (p.20). o passo seguinte, e fundamental, diz Chauí, é que a ideologia passa a elaborar o imaginário das representações, falando sobre a sociedade, sobre o político, pretendendo dizer o que elas são em si. 
7. “[...] se há convertido en una seudoformación socializada, en la ubicuidad del espíritu enajenado, que, según su gênesis y su sentido, no precede a la formación cultural, sino que la sigue. De este modo, todo queda apresado en las mallas de la socialización y nada es ya naturaleza a la que no se haya dado forma; pero su tosquedad - la vieja ficción - consigue salvarse la vida tenazmente y se reproduce ampliada: cifra de una conciencia que há renunciada a la autodeterminación, se prende inalienablemente elementos culturales aprobados, si bien éstos gravitan bajo su malefício, como algo descompesto, hacia la barbárie. [...] Incluso el que la seudoformación haya pasado a ser la forma dominante de la conciencia ctual, pese a toda la ilustración y a toda la información que se difunde - y con su ayuda - exige una teoria que tome todo más ampliamente" (AdORNo, 1966, p.175-176).

\section{REFERÊNCIAS}

ADORNO, Theodor, W. Educação e emancipação. Trad. Wolfgang Leo Maar. Rio de Janeiro: Paz e Terra, 2006.

. Teoria de la seudocultura. In: ADORNO e HORKHEIMER. Sociologica. Trad. Victor Sánchez de Zavala (versión espanõla). Madrid: Taurus, 1966, p.175-199.

ARENDT, H. A vida do espirito: o pensar, o querer, o julgar. Trad. Antonio abranches. Rio de Janeiro: Relume Dumará, 2000.

ARISTÓTELES. Política. Trad. Mário da Gama Kury. 3.ed. Brasília: Editora UnB, 1997.

CHAUÍ, M. Crítica e ideologia. Cadernos SEAF, ano 1, 1978, p.17-32.

CONFERÊNCIA MUNDIAL SOBRE EDUCAÇÃO PARA TODOS. Declaração Mundial sobre a Educação para Todos. Satisfação das necessidades básicas de aprendizagem. Jomtien, Tailândia, 1990. Brasília: MEC, 1993.

COÊLHO, I. M. A educação, a cultura e a invenção de uma outra escola. In: ENCONTRO DE PESQUISA EM EDUCAÇÃO DO CENTRO-OESTE, 4, 2003, Campo Grande. Anais. Campo Grande: UCDB; UFMS, 2003. p.1-10.

DELORS, J. Educação um tesouro a descobrir. Relatório para a Unesco da Comissão Internacional sobre a educação para o século XXI. Trad. José Carlos Eufrásio. São Paulo: Cortez, 2001.

EVANGELISTA, E. G. S. A Unesco e o mundo da cultura. Brasília, DF: Unesco/ Goiânia: Ed. UFG, 2003.

. Educação e mundialização. Goiânia: Ed. UFG, 1997. 
FAURE, E. Preâmbulo. In: Aprender a ser. Trad. Maria Helena Cavaco e Natércia Paiva Lomba. São Paulo: Livraria Bertrand, 1972.

HORKHEIMER, M. Teoria crítica: uma documentação. Tomo I. Trad. Hilde Cohn. São Paulo: Perspectiva: Edusp, 1990.

HORKHEIMER, M.; ADORNO, T. Dialética do esclarecimento: fragmentos filosóficos. Trad. Guido Antonio de Almeida. Rio de Janeiro: Jorge Zahar Ed., 1985.

. Ideologia. In:___. Temas básicos da sociologia. Trad. Álvaro Cabral. São Paulo: Cultrix: Edusp, 1973, p.184-205.

IANNI, O. Teorias da globalização. Rio de Janeiro: Civilização Brasileira, 1995.

A política mudou de lugar. In: DOWBOR, L.; IANNI, O.; RESENDE, P. (orgs). Desafios da globalização. Petrópolis, Rio de Janeiro: Vozes, 1998, p.17-27.

. A história da mundialização. In: . A sociedade global. 7 ed. Rio de Janeiro: Civilização Brasileira, 1999, p.53-68.

. O cidadão do mundo. In: Capitalismo, violência e terrorismo. Rio de Janeiro: Civilização Brasileira, 2004, p.103-114.

KANT, I. Resposta à pergunta: que é o iluminismo? In: . A paz perpétua e outros opúsculos. Trad. Artur Morão. Lisboa: Edições 70, 2004.

MAAR, W. L. À guisa de introdução: Adorno e a experiência formativa. In: Educação e emancipação. 3.ed. Trad. Wolfgang Leo Maar. São Paulo: Paz e Terra, 2006, p.11-28. 